\title{
Heavy Metals Concentrations and Health Risk in Vegetables Grown in Xigu Industrial District in Lanzhou City
}

\author{
Jean Yves Uwamungu, Yufeng Jiang, Anne Marie Mukundwa, Hang Sun, and Xuefei Hu
}

\begin{abstract}
These experiments were carried out to analyze the content of heavy metals in 8 kinds of vegetables grown in Xigu Industrial District in Lanzhou city. The possible health risk associated with 4 metals in vegetables to local inhabitants via their consumption was assessed, based on target hazard quotients (THQ) and pollution indexes. The results showed that the measured vegetables do not contain $\mathrm{Pb}$ or maybe $\mathrm{Pb}$ content in vegetables is relatively small, it could not be measured in this experiment. For $\mathrm{Cu}$ elements, the most abundant content was in eggplant with a concentration of $0.067 \mathrm{mg} / \mathrm{kg}$, then the least content was for cauliflower with a concentration of $0.015 \mathrm{mg} / \mathrm{kg}$; for Cd elements, the most abundant content was in celery with a concentration of $0.067 \mathrm{mg} / \mathrm{kg}$, the content in cabbage was the least with a concentration of $0.023 \mathrm{mg} / \mathrm{kg}$; and then for $\mathrm{Zn}$ elements, the most abundant content was in spinach with a concentration of $1.001 \mathrm{mg} / \mathrm{kg}$, the least is pepper with a concentration of $0.274 \mathrm{mg} / \mathrm{kg}$. Environmental health risk assessment showed that THQ values are less than 1, indicating the heavy metal content of most collected vegetables match with the requirements of safety and quality of agricultural products.
\end{abstract}

Index Terms - Health risk, heavy metals, industrial district, vegetables.

\section{INTRODUCTION}

Vegetables are important in people's daily diet, and provide to the body essential vitamins, minerals, fibers and many other nutrients [1]. With the rapid economic development, the people's living standards have known a corresponding increase, and there must be taken attention to the quality of vegetables. Due to the rapid development of China's urbanization, industrialization and agricultural intensification processes, environmental pollution, especially agricultural soil pollution, agricultural safety issues caused by the soil quality of the environment has increasingly become severe [2]. Heavy metal pollution has long-term cumulative effects and interactions, considering their environmental effects related to soil, water, plants, animals and humans [3].

Accumulation of heavy metals in vegetables may affect the growth and development of vegetables; enter the body

Manuscript received January 5, 2017; revised March 24, 2017.

Jean Yves Uwamungu is with the Center for Agricultural Resources Research, Institute of Genetics and Developmental Biology, Chinese Academy of Sciences, Shijiazhuang 050021, China (e-mail: joady9@yahoo.fr, joady9@mails.ucas.ac.cn ).

Yufeng Jiang, Anne Marie Mukundwa, Hang Sun, and Xuefei Hu are with the School of Environmental and Municipal Engineering, Lanzhou Jiaotong University, Lanzhou 730070, China (e-mail: jiangyf7712@126.com,mukie@yahoo.fr ). through the food chain on the human health impact. Although soil heavy metal pollution has an important buffer, but the heavy metal content exceeds effect concentration, especially on crops accumulation of heavy metals in the food chain can produce unpredictable results [4]. Due to the impact of vegetables' pollution on human health, to carry out a risk assessment of heavy metals in vegetables, vegetable guide for safe consumption, promote the development of vegetable industry has an important significance [5].

Taking Xigu District of Lanzhou City, growing vegetables for the study were analyzed vegetable samples content $\mathrm{Cu}$, $\mathrm{Cd}, \mathrm{Pb}, \mathrm{Zn}$, and vegetable contamination by heavy metals in the analysis and evaluation of the health risks and safety of vegetables were discussed. Analysis and evaluation of potentially dangerous heavy metal contamination of soil vegetable grasp vegetable production soil environment, reducing the heavy metal content in vegetables, vegetables improve quality, and guarantee people's food security and the promotion of sustainable development of vegetable industry are of great significance.

\section{MAterials AND Methods}

\section{A. The Main Instruments and Reagents}

AA220Z atomic absorption spectrophotometer, lead, cadmium, copper, zinc and other elements of the hollow cathode lamp, electric stove, beakers, flasks, $50 \mathrm{~mL}$ crucibles, pipettes and graduated cylinders,

Concentrated nitric acid (excellent pure); perchloric acid (pure); 30\% hydrogen peroxide (pure), lead, cadmium, copper, zinc standard solution (concentration of $1000 \mathrm{mg} / 1$, National Research Center),Deionized water, etc.

\section{B. Material Acquisition and Preprocessing}

Fresh vegetables and edible parts as samples were chosen, the collected vegetables were immediately put into a plastic bag to prevent moisture loss, which could cause their moisture content determination become inaccurate. Samples were taken back to the lab, and immediately the leaves and roots were washed with tap water. When there is no water in the vegetable surface, vegetables were weighed each about $20 \mathrm{~g}$ to determine the moisture content, all samples (including samples of vegetables used to measure water use) chopped on heated blast oven baked at $60{ }^{\circ} \mathrm{C}$ about two days, after the samples were then crushed prototype eleven pulverized, were placed in a sealed and labeled bag, the last saved backup for analysis in a dryer. 


\section{Determination of Heavy Metal Element Content}

For the determination of heavy metal samples, the atomic absorption spectrometry method has been used in this experiment. The experiment measured four kinds of heavy metals in vegetables: zinc, copper, lead and cadmium. Specific heavy metal content determination method is: accurately weighed on the analytical balance of $1.0 \mathrm{~g}$ of plant sample powder, placed in a capacity of $50 \mathrm{ml}$ crucible, then add $20 \mathrm{~mL}$ digestion solution (in the concentration ratio of nitric acid: perchloric acid $=5: 1$ ), cover the crucible cover then soaked for 12 hours, and heated slightly on the heating plate until the sample particles melt, and then add 5-10mL digestion, shaked, and gradually heated, the solution gradually thickens, the color becomes brown Red, paying attention to the process of heating to prevent ashing. Continue to add 5-10mL digestion, until when the sample color is no longer brown; turns to red, and then wait until the solution is digested until it becomes transparent (colorless), or light yellow, lowering the temperature to continue heating to the solution, taking a thick white smoke, and yellow-white residue so far. The cooling removal, with a filter into the $50 \mathrm{~mL}$ volumetric flask, and diluted with deionized water to the mark, using atomic absorption spectrometry was determined.

\section{Evaluation Method and Pollution Standards of Heavy Metals in Vegetables}

The single factor pollution index method and Nemerow integrated pollution index method were used in the evaluation [6] and [7].

\section{1) Single factor pollution index method}

The single pollution index was used to evaluate the pollution degree of heavy metals in vegetables:

$$
P_{i}=\frac{C_{i}}{S_{i}}
$$

where, $P$ is the single pollution index of pollutant $i$; $C_{i}$ is the measured value $(\mathrm{mg} / \mathrm{kg})$ of pollutant $i ; S_{i}$ is the evaluation standard $(\mathrm{mg} / \mathrm{kg})$ of pollutant $i$.

\section{2) Nemerow integrated pollution index method}

As the single pollution index can only reflect the pollution of various pollutants, it cannot fully and comprehensively reflect the pollution of vegetables, and the pollution index that takes into account the single pollution index average and the highest value, can highlight the pollution of heavy pollutants effect.

The calculation formula is:

$$
P_{\text {综 }}=\sqrt{\frac{\left(P_{i}\right)_{\max }^{2}+\left(\frac{1}{n} \sum_{i=1}^{n} P_{i}\right)^{2}}{2}}
$$

where, $P_{\text {综 }}$ is the total mechanized heavy metal pollution index; $\left(P_{i}\right)$ max contaminants in soil pollutant dye maximum index; $\frac{1}{n} \sum_{i=1}^{n} P_{i}$ as the average of pollutants.
TABLE I: HEAVY METAL POLLUTION INDICES AND THE CORRESPONDING POLLUTION DEGREES OF THE VEGETABLES

$\begin{array}{cccc}\text { Classificatio } & \text { pollution } & \text { Integrated pollution } & \text { Pollution level } \\ \mathrm{n} & \text { index } & \text { level } & \text { Safe } \\ 1 & \mathrm{p} \leq 0.7 & \text { safe } & \text { Clean } \\ 2 & 0.7<\mathrm{P} \leq 1.0 & \text { warn } & \text { Light } \\ 3 & 1<\mathrm{P} \leq 2.0 & \text { light } & \text { Moderate } \\ 4 & 2<\mathrm{P} \leq 3.0 & \text { moderate } & \text { strong, severe } \\ 5 & \mathrm{P}>3 & \text { heavy } & \end{array}$

\section{3) Human health risk assessment}

(THQ) was used to assess the health risk of heavy metals in the Lanzhou area through the intake of vegetables, according to the health risk concentration proposed by the US Environmental Protection Agency (EPA) in 2000 [8]. The method is based on the US EPA (2000) proposed method for the adult and the average weight of children, which established the risk analysis method for different age groups of different parameters. The formula is:

$$
T H Q=\frac{E_{F} \times E_{D} \times E_{I R} \times C}{R_{F D} \times W_{A B} \times T_{A}} \times 10^{-3}
$$

where $E_{F}$ is the exposure frequency ( $\left.365 \mathrm{~d} / \mathrm{a}\right) ; E_{D}$ is the exposure duration (70 a); EIR for the exposure inhalation rate $(\mathrm{g} /($ person $\bullet \mathrm{d})) ; C$ is the heavy metals content nutrients $(\mathrm{mg} /$ $\mathrm{kg})$; RFD as a reference dose $(\mathrm{mg} /(\mathrm{kg} \bullet \mathrm{d}))$, $W_{A B}$ for the average human body weight to heavy metals (for adults $55.9 \mathrm{~kg}$, and for $32.7 \mathrm{~kg}$ children); $T_{A}$ is the average exposure time. The results THQ $<1$, indicating no pollutants affect human health ( not obvious); THQ> 1 , indicating that the contaminant can cause human health risks, large THQ value indicates that the risk on human health is high.

4) Data analysis

Data analysis and statistical analysis were performed using Excel 2010 and SPSS software.

\section{RESULTS AND DISCUSSIONS}

While analyzing vegetable samples, most of them matched with the pollution degree requirements shown in Table I, and below are some analyses done during the research:

\section{A. Analysis of Water Content in Vegetables}

As shown in Table II, the maximum water content in vegetables has been found in spinach, whereas the minimal water content has been found in peppers, the results showed that the water content of the selected experiments leafy vegetables is generally higher than the class roots, fruits and vegetables. Fruits and vegetables displayed content of heavy metals with high moisture content, consistent with the previous reports. Studies have shown that some of the short growth cycle of vegetables is due to the content of heavy metals in vegetables such as leeks, green onions, etc. Although not relatively low moisture content, but because of their growth cycle is short, thus leading to the enrichment of heavy metals in soil from a relatively short time, thus resulting in the accumulation of heavy metals in vegetables rather small [9]. 
TABLE II: RESULTS OF WATER CONTENT OF VEGETABLE SAMPLES

\begin{tabular}{lcccccccc}
\hline Species & eggplant & pepper & cabbage & celery & squash & radish & spinach & Cauliflower \\
\hline Water content & $94.23 \%$ & $92.67 \%$ & $94.13 \%$ & $95.28 \%$ & $94.98 \%$ & $92.81 \%$ & $96.43 \%$ & $93.39 \%$ \\
\hline
\end{tabular}

\section{B. Analysis of Heavy Metals in Vegetables}

Experimentally, in eight kinds of vegetables, $\mathrm{Cu}, \mathrm{Cd}, \mathrm{Pb}$, $\mathrm{Zn}$ (four heavy metals) contents have been measured. The results showed that the content difference between the measured heavy metals in vegetables is greater for $\mathrm{Cu}$ element, its content size relationship is in the order of eggplant $>$ spinach $>$ celery $>$ cabbage $>$ pepper $>$ radish $>$ squash $>$ cauliflower, its content in the range $0.015-0.067 \mathrm{mg} /$ $\mathrm{kg}$, an average of $0.04 \mathrm{mg} / \mathrm{kg}$; as it is noticed from Table III, for Cd elements, the content in a decreasing order of celery> spinach> cauliflower> eggplant> pepper> squash> radish> cabbage, its content in the range $0.023-0.067 \mathrm{mg} / \mathrm{kg}$, an average of $0.044 \mathrm{mg} / \mathrm{kg}$; for $\mathrm{Zn}$ element, the content of the relationship between the size of the order of spinach > celery> squash> cauliflower> radish> eggplant> cabbage> pepper amount ranging from $0.274-1.001 \mathrm{mg} / \mathrm{kg}$, an average of $0.483 \mathrm{mg} / \mathrm{kg}$, none of $\mathrm{Pb}$ is detected, it may be considered that Lanzhou xigu area greenhouses do not contain the $\mathrm{Pb}$ elements or $\mathrm{Pb}$ content is too small, it has been below the standard limit of detection in this experiment which explains that it cannot be harmful as it is shown in Table IV.

TABLE III: THE CONTENTS OF HEAVy Metals IN DifFERENT VeGETABLES $(\mathrm{MG} / \mathrm{KG})$

\begin{tabular}{ccccccccc}
\hline & $\begin{array}{c}\text { egg } \\
\text { pla }\end{array}$ & $\begin{array}{c}\text { pepp } \\
\text { er }\end{array}$ & cabba & cele & squa & radi & spina & cauliflo \\
& nt & & sh & sh & ch & wer \\
\hline $\mathrm{Cu}$ & 0.0 & 0.02 & & 0.05 & 0.02 & 0.02 & & \\
& 67 & 5 & 0.049 & 6 & 2 & 3 & & \\
$\mathrm{Cd}$ & 0.0 & 0.04 & & 0.06 & 0.03 & 0.02 & & \\
$\mathrm{~Pb}$ & 44 & 2 & 0.023 & 7 & 9 & 9 & & \\
& $\mathrm{nd}$ & $\mathrm{nd}$ & $\mathrm{nd}$ & $\mathrm{nd}$ & $\mathrm{nd}$ & $\mathrm{nd}$ & $\mathrm{nd}$ & $\mathrm{nd}$ \\
$\mathrm{Zn}$ & 0.3 & 0.27 & & 0.54 & 0.51 & 0.40 & & \\
& 53 & 4 & 0.316 & 3 & 5 & 6 & & \\
\hline
\end{tabular}

nd: not detected.

In comparison with the standards of national food hygiene standards, only the cadmium (Cd) was exceeded in the standard of the national food hygiene standards, the celery $(0.067 \mathrm{mg} / \mathrm{kg})$ and the spinach $(0.060 \mathrm{mg} / \mathrm{kg})$ exceeded the standards, and other vegetables were also close to the safety requirements of the free-pollution vegetables (Cauliflower in the $\mathrm{Cd}$ element content), the standard requirements of $0.050 \mathrm{mg} / \mathrm{kg}$, so that the long-term consumption of foodstuffs, such as cauliflower, eggplant and pepper, are more than $0.040 \mathrm{mg} / \mathrm{kg}$, and some even reached $0.049 \mathrm{mg} /$ These vegetables may have a certain impact on human health.

TABLE IV: MAXIMUM LEVELS OF CONTAMINANTS IN VEGETABLES

\begin{tabular}{lll}
\hline Heavy metal & Vegetable limit standards $\left(\mathrm{mg} \cdot \mathrm{kg}^{-1}\right)$ & Standard code \\
\hline $\mathrm{Cu}$ & 10 & GB 15199-1994 \\
$\mathrm{Zn}$ & 20 & GB 13106-1994 \\
$\mathrm{Pb}$ & 0.2 & GB 2762-2005 \\
$\mathrm{Cd}$ & 0.05 & GB 2762-2005 \\
\hline
\end{tabular}

\section{Heavy Metal Pollution Degree in Different Vegetables}

The heavy metal pollution degree in different vegetables was different, and Table $\mathrm{V}$ lists the evaluation results of 8 kinds of heavy metal pollution in vegetables. According to the analysis of the status of heavy metal pollution on different vegetables in the sample, it can be obtained: Vegetables of different types, different conditions of the same heavy metal absorption, and the absorption of different heavy metals in vegetables are all different. This may be due to a variety of factors such as; the absorption of heavy metal elements in the process of vegetables to be affected [10], the size of a soil heavy metal content of heavy metals in vegetables, the degree of pollution and the nature of heavy metal elements, on the other hand, each vegetable itself has specific absorption characteristics on different heavy metals. He Jianghua, Liu Yong and other studies have shown that, in different vegetables, little enrichment coefficient of $\mathrm{Pb}$, the poor mobility and lead in soils, and the mobility of $\mathrm{Cd}$ in soil is strong, and the absorption capacity of plants to cadmium is also strong [11]. Therefore, this experiment measured the $\mathrm{Cd}$ element content as relatively high, $\mathrm{Pb}$ element content is too low, and before the relevant report is consistent with.

As it can be seen from Table V, apart from celery and spinach, other vegetables heavy metal content of single pollution index and integrated pollution evaluation are in a clean range; meaning it has been found that the pollution level is safe and clean as it has been explained in Table $1 ; \mathrm{Cd}$ content exceed the standard 1.34 times; evaluation of spinach single pollution index for light pollution can also be dangerous.

\section{Human Health Risk Assessment of Heavy Metals Intake by Local Residents}

In order to further analyze the health risk of heavy metals to the human body, the THQ method was used to evaluate the health risk of heavy metals in local residents (adults and children) by means of edible vegetables [12] and [13].

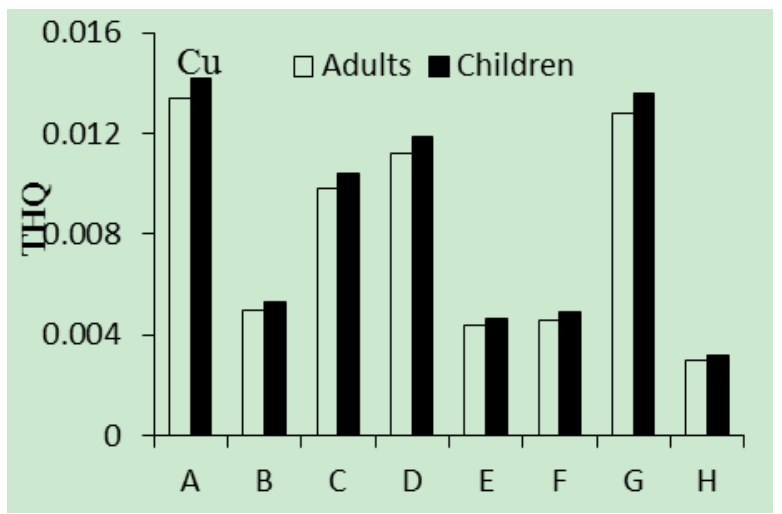

Fig. 1. Evaluation of local residents' (adults and children) health risk of heavy metals in edible vegetables using target hazard quotients for $\mathrm{Cu}$.

Local residents (adults and children) into the body through the vegetable exposure to exposure to heavy metals $\mathrm{Cu}, \mathrm{Cd}$ and $\mathrm{Zn}$ THQ values were expressed in Fig. 1-Fig. 3 respectively. From the graphs, the value of THQ of heavy 
metal in children is higher than that of adults, indicating that children eat more vegetables than adults. We can also see the Cd THQ value is the highest, in 0.195 to 0.568 , less than 1 , while the $\mathrm{Cu}$ and $\mathrm{Zn}$ value of THQ is small, is far less than 1, indicating the health risk of such heavy metals produced by the way of vegetables is not obvious. This shows that the health risk of heavy metals in vegetables in Lanzhou City, Xigu District, caused by the low consumption of these vegetables is relatively safe.

TABLE V: Evaluation Results of HeAvy Metal Pollution By Using Single Factor IndeX AND NEMEROW INTEGRATIVE Pollution INDEX IN VEGETABLES

\begin{tabular}{|c|c|c|c|c|c|c|c|}
\hline \multirow{2}{*}{ Project } & \multicolumn{4}{|c|}{ Single pollution index } & \multirow{2}{*}{$\begin{array}{l}\text { Single pollution index } \\
\text { Assessment result }\end{array}$} & \multirow{2}{*}{$\begin{array}{c}\text { Integrated } \\
\text { pollution index }\end{array}$} & \multirow{2}{*}{$\begin{array}{l}\text { Integrated pollution } \\
\text { index } \\
\text { Assessment result }\end{array}$} \\
\hline & Cus & $\mathrm{Zn}$ & $\mathrm{Pb}$ & $\mathrm{Cd}$ & & & \\
\hline Eggplant & 0.007 & 0.018 & - & 0.88 & Safe, clean & 0.658 & Safe, good \\
\hline Pepper & 0.003 & 0.014 & - & 0.84 & Safe, clean & 0.627 & Safe, good \\
\hline Cabbage & 0.005 & 0.016 & - & 0.46 & Safe, good & 0.344 & Safe, good \\
\hline Celery & 0.006 & 0.027 & - & 1.34 & $\begin{array}{l}\text { Light, less } \\
\text { contaminated }\end{array}$ & 1.06 & $\begin{array}{l}\text { Light, less } \\
\text { contaminated }\end{array}$ \\
\hline Squash & 0.002 & 0.026 & - & 0.78 & Safe, clean & 0.583 & Safe, good \\
\hline Radish & 0.002 & 0.020 & - & 0.58 & Safe, good & 0.434 & Safe, good \\
\hline Spinach & 0.006 & 0.050 & - & 1.20 & $\begin{array}{c}\text { Light, less } \\
\text { contaminated }\end{array}$ & 0.898 & Warning line \\
\hline Cauliflower & 0.005 & 0.023 & 一 & 0.98 & Warn & 0.733 & Warn \\
\hline
\end{tabular}

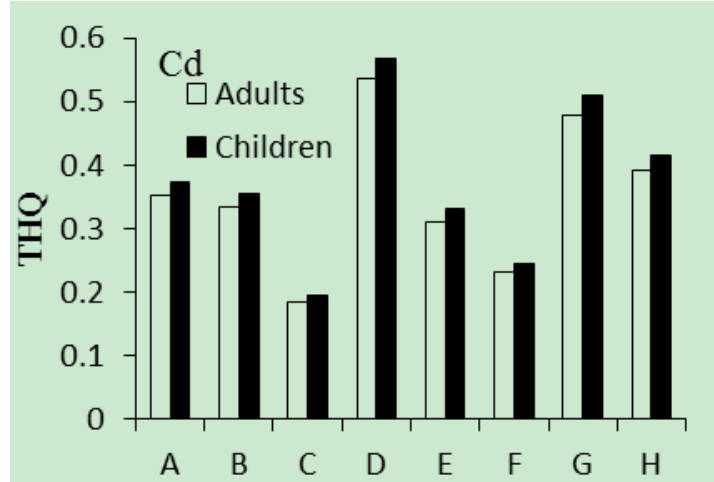

Fig. 2. Evaluation of local residents' (adults and children) health risk of heavy metals in edible vegetables using target hazard quotients for $\mathrm{Cd}$.

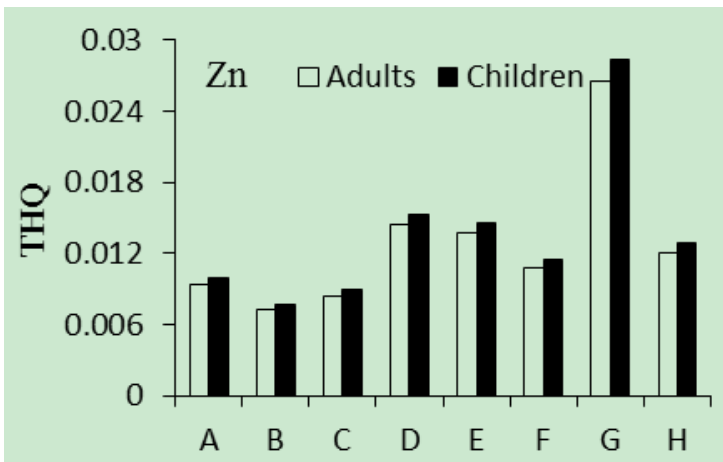

Fig. 3. Evaluation of local residents' (adults and children) health risk of heavy metals in edible vegetables using target hazard quotients for $\mathrm{Zn}$, where A: Eggplant, B: Pepper, C: cabbage, D: Celery, E: Squash, F: Radish, G: Spinach and H: Cauliflower.

\section{REFERENCES}

[1] P.-F. Qin et al., "Soil and vege tables of different functional areas in the industrial city of heavy metal pollution and health risk assessment[J]," Chinese Journal of Ecology, 2010, vol. 19, no. 7, pp. 1668-1674.

[2] Y. Qi et al., "The status and research progress of heavy metal pollution in vegetables in China [J]," Anhui Agricultural Science, 2015, vol. 43 , no. 6 , pp. 255-257.
[3] X. Li and Y. Zhang, "Current situation of heavy metal pollution in vegetable and vegetable soil in China and its general rules [J]," Sichuan Environment, 2008, vol. 27, no. 2, pp. 94-97.

[4] M.-F. Cai et al., "Study on the current situation and Control Countermeasures of heavy metal pollution in cultivated land in China [J]," Environmental Science and Technology, 2014, vol. 37, no. 120, pp. 223-230.

[5] R.-Z. Li et al., "Heavy metal pollution in vegetables and vegetable sporadic typical nonferrous metal mining city and health risk assessment of [J]," Environmental Science, 2013, vol. 34, no. 3, pp. 1076-1085.

[6] P. Qi et al., "Evaluation and health risk analysis of typical heavy metals in soil vegetable system in Lanzhou city [J]," Arid Area, 2012, vol. 35, no. 1 , pp. 162-170

[7] S.-X. Yang et al., "Wave, cable, melodious. The status of Huayuan mining area of heavy metal pollution of vegetables in Xiangxi and health risk assessment [J]," Journal of Agro Environment Science, 2012, vol. 31, no. 1, pp. 17-23.

[8] Q.-B. Sun et al., "Soil and vegetable heavy metal pollution characteristics and health risk assessment in Daye mining area," Environmental Chemistry, 2013, vol. 32, no. 4, pp. 671-677.

[9] H.-M. Wu, "Effects of greenhouse cultivation on the migration and accumulation of heavy metals in vegetables [D]," Zhejiang University of Technology, 2012.

[10] A survey analysis of heavy metals bio-accumulation in internal organs of sea shell animals affected by the sustainable pollution of antifouling paints used for ships anchored at some domestic maritime spaces[J]. Chinese Science Bulletin, 2008, vol. 53, no. 16, pp. 2471-2475.

[11] K.-H. Wu et al., "In the process of city vegetable base and causes of soil heavy metal pollution assessment - A case study of Shenzhen city [J]," Chinese Soil and Fertilizer, 2011, no. 4, pp. 83-89.

[12] Y. Yu, "Tianjin City leafy vegetables and soil heavy metal content investigation and risk assessment of [D]," Northwest Agriculture and Forestry University, 2013.

[13] C.-S. Qu, "Health risk assessment and control of heavy metal pollution [D]," Nanjing University, 2011.

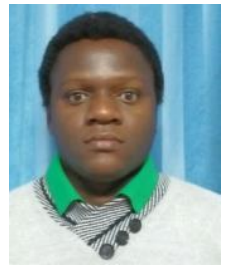

Jean Yves Uwamungu was born in Rwanda, on September $26^{\text {th }}, 1986$. He got the bachelor of chemistry at the National University of Rwanda (2011), the master of science in environmental science at Lanzhou Jiaotong University (2016), CAS TWAS (Chinese Academy of Sciences, the World Academy of Sciences) PhD Fellow at the Center for Agricultural Resources Research, Institute of Genetics and Developmental Biology, Chinese Academy of Sciences, Shijiazhuang city, Hebei Province (2016-2020). His research interest is soil environmental chemistry and ecology. 
Yufeng Jiang was born in China. Yufeng Jiang got the bachelor of analytical chemistry at the North University of China (2000), the master of science in analytical chemistry at Northwest Normal University (2006), the PhD in environmental engineering at Shanghai University. Yufeng Jiang's research interest is soil environmental chemistry, environmental pollution and control.

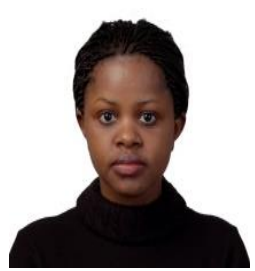

Anne Marie Mukundwa was born in Rwanda, on September $09^{\text {th }}$, 1989. She got the bachelor of soil and environmental management at the National University of Rwanda (2014), the master of science in environmental science at Lanzhou Jiaotong University (2014-2018). Her research interest is environmental phytoremediation, soil pollutants removal. 